Computer Applications to Paleolimnology

\title{
A useful tool for image enhancement
}

\author{
Norman A. Andresen \\ Herbarium, The University of Michigan, 1109 Geddes Avenue, Ann Arbor, MI 48109-1079, USA; (e-mail: \\ andresen@umich.edu)
}

Received 12 December 2002; accepted in revised form 11 April 2003

Keywords: Image enhancement, Computer applications, Diatoms, Digital technique, Microscopy

\begin{abstract}
Image enhancement provides a means to facilitate information transfer without altering the image information. A plug-in for the commonly used image capture and manipulation program Photoshop ${ }^{\mathrm{TM}}$ is discussed as one useful tool.
\end{abstract}

\section{Introduction}

Image gathering, processing, and eventual illustration production are common steps familiar to paleolimnologists. Here I discuss a technique particularly useful to investigators dealing with very small organisms, particularly some species of diatoms. In the past line drawings, either produced with a camera lucida, or measured drawings (Hartley et al. 1996) were the most generally accepted method for illustrations of such microfossils. Common criticisms of these methods were the amount of artistic talent and labor required and the opportunities for 'interpretation'. In the best case the degree of interpretation was for the most part smoothing of outlines and other similar minor corrections. In at least a few cases there were significant alterations that resulted in misrepresentations of the specimen. Pursuit of an idealized shape was usually the goal. The extreme of this case are the idealized geometrical illustrations of some authors (e.g., Schumann 1862-1869).

Photography has been used to record microscopic organisms for over a century. However, it was not widely adopted until quite recently. Photographs were reproduced in Le Diatomiste (1892-1893) and eventually in Schmidt's Atlas (1874-1959) by the late 1950s. The advent of electron microscopes (transmission electron microscope - TEM and Scanning
Electron Microscopes - SEM) necessitated photographic reproduction. With the TEM the image was sometimes hard to interpret for some of the structures. Specific sample treatments such as carbon replicas could provide images with three-dimensional appearance (Drum 1967). The Helmke and Krieger series (Helmke and Krieger 1953-1977) relied heavily on photography, sometimes in stereo pairs, but also relied quite heavily on artist's reconstructions. Hustedt employed photography in the later portions of the Kieselalgen (1962-1966) but it was mostly limited to representation of large cells. Printing technology of the day had limitations, and relatively few scientists had the time, patience, and training to fully exploit techniques that were available. Simonsen (1987) demonstrated the improvements in printing technology with his reproductions of Hustedt types. Krammer's (1982) addition to the Helmke and Krieger series (1953-1977) marked the end of individual plates and the continuation of the series as books because of the improvement in printing technology.

Photography has slowly become the preferred medium for recording and eventually disseminating observations. As photography evolved into the digital age, image-handling programs have largely supplanted film and chemicals as the preferred method to prepare images for publication. The digital medium offers observers an array of tools to extract infor- 


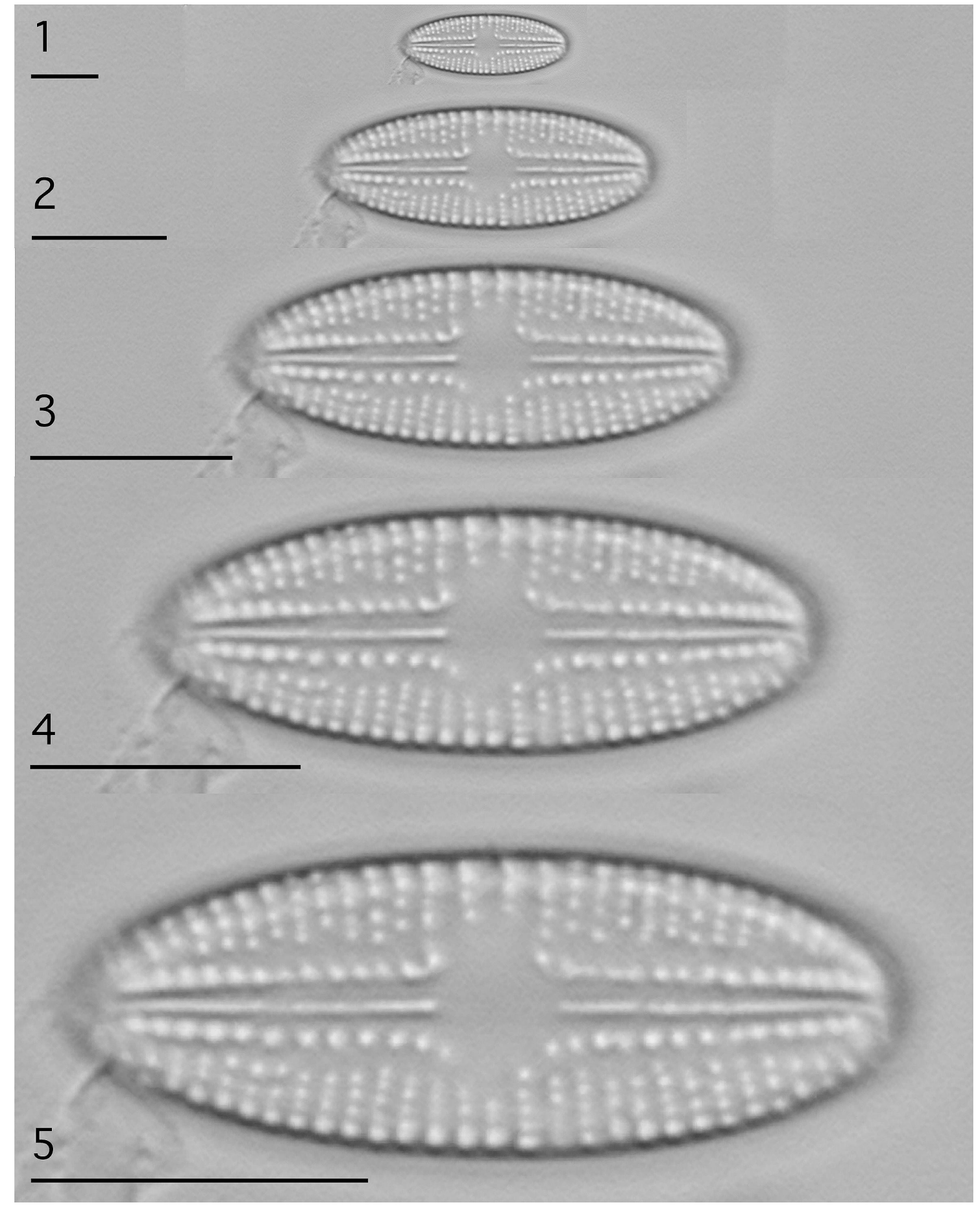

Figure 1. Digital image of Navicula farta Hust. the original image capture, $1250 \times$. Scale bar $=10 \mu \mathrm{m}$. Figure 2. Digital image of Navicula farta Hust. at 200\% enlargement of Figure 1. Scale bar $=10 \mu \mathrm{m}$. Figure 3. Digital image of Navicula farta Hust. at $300 \%$ enlargement of Figure 1. Scale bar $=10 \mu \mathrm{m}$. Figure 4. Digital image of Navicula farta Hust. at $400 \%$ enlargement of Figure 1. Scale bar $=10 \mu \mathrm{m}$. Figure 5. Digital image of Navicula farta Hust. at 500\% enlargement of Figure 1. Scale bar $=10 \mu \mathrm{m}$. 
mation from images (Stoermer 1996; Wunsam and Bowman 2001).

However, specific problems of camera resolution capabilities and image processing are no less important in the digital realm. The algorithms employed by various processing programs vary in their capability to render image size changes. Photoshop ${ }^{\mathrm{TM}}$ has not had adequate algorithms within the image size submenu to render enlarged images with the same resolution as the original. A plug-in for Photoshop ${ }^{\mathrm{TM}}$ is available which employs fractal technology to change sizes without resolution loss. The program, Genuine Fractals ${ }^{\mathrm{TM}}$, manufactured by LizardTech, Inc. is a plug-in for Photoshop ${ }^{\mathrm{TM}}$ that enables a user to scale images, larger or smaller, while maintaining the quality of the original. The advanced proprietary fractal technology creates files claimed to be 'resolution-independent':

"This means that Genuine Fractals eliminates the relationship between pixels and resolution by mathematically encoding the image using an algorithm that replaces the pixels with a new file structure. When you next open the file, you can re-scale it to the desired size and the plug-in will generate new pixels while maintaining sharpness regardless of image size."

(used with permission from LizardTech).

The question to ask is, "Does it really work?" Small diatoms have always presented observation and recording problems. So, to test the plug-in, we conducted trials on images gathered on our system with small diatoms (Figure 1). Our system is a Leitz ${ }^{\mathrm{TM}}$ DMRX with a full immersion optical system (100X, 63X and 40X) capable of NA 1.4. The digital camera is a Sony DKC5000 which ports its image directly into Photoshop ${ }^{\mathrm{TM}}$, running on a Macintosh ${ }^{\mathrm{TM}}$ Power PC computer, at 400 dpi. Thus we start with a high resolution image (Figure 1). Figures 2 through 5 are increasing levels of enhancement from $200 \%$ to $500 \%$ enlargement. As the image is enlarged the deficiencies of the original image become obvious while the plugin appears to accomplish its claims.

The steps in this process are remarkably straight forward. Once an image is gathered, the Save As command is used and the file format is selected as Genuine Fractals $^{\mathrm{TM}}$. A dialog box appears asking for the type of image. The file is saved and then closed. Upon opening the Genuine Fractals ${ }^{\mathrm{TM}}$ (*.stn) file, the plug-in is invoked and this is where the various enhancement features are selected. The only step to remember when saving the enhanced image it to choose Save As and the desired file type and not just Save and create another Genuine Fractals ${ }^{\mathrm{TM}} *$.stn file.

Application of this digital tool is useful to enlarge images of small specimens which, in the originally gathered image, results in small prints. With small images, some details are difficult to view and enlarging the image greatly improves the visual aspect. Theoretically, the digital image has the potential to be enlarged to a great degree. Although the Genuine Fractals manual suggests the program works best up to $600 \%$ increase, the manual provides a method to obtain an $800 \%$ increase. As the description of the program states, the original image is enlarged faithfully up to $600 \%$ without loss of sharpness. The alteration of the digital information occurs in the image program, i.e. Photoshop ${ }^{\mathrm{TM}}$ or NIH-Image, not the plug in.

The plug-in can also be used to reduce image size. In laboratories that still use Polaroid film imaging with the SEM, the resulting print is usually scanned and then incorporated into a digital plate. The scanned image is generally large and in many cases this large image is not practical. Traditionally, a smaller print than that which came from the camera was made from a negative. The same process of image reduction can be accomplished with the plug-in. Modern SEMs with digital image capture eliminate such darkroom work.

Compared to conventional photography the digital world offers a host of opportunities (Wunsam and Bowman 2001; McJonathan 2000; Valdecasas et al. 2002) which will not only improve our capabilities to transmit information but also permit use to gather information in ways we have yet to imagine.

\section{Acknowledgements}

Quotation from the Genuine Fractals ${ }^{\mathrm{TM}}$ manual are used with permission of LizardTech, Inc. The work was partially support by Cooperative Agreement GL005477 from the Great Lakes National Program Office, U.S. Environmental Protection Agency, Region V. I want to thank Dr. E.F. Stoermer for his comments for improving the manuscript.

\section{References}

Le Diatomist 1892-1893. Par J. Tempère. Paris. Vols. I and II. 
Drum R.W. 1967. Carbon replicas of siliceous sponge spicules. Science 157: 581-582.

Hartley B., Barber H.G. and Carter. J.R. 1996. An Atlas of British Diatoms. Sims P. (ed). Biopress, Bristol, 601 pp.

Helmke J.G. and Krieger W. 1953-1977. Diatomeenschalen im elektronenmikroskopischen Bild. 1-10: 1-1023. Lehre.

Hustedt F. 1962-1966. Kieselalgen in L. Rabenhorsts Kryptogammenflora von Deutschlands, Österreich und der Schweiz. Band 7, Heft 3, Leif 2-4, pp. 161-816.

Krammer K. 1982. Valve morphology in the genus Cymbella C. A. Agardh. In: Helmke J.-G. and Krammer K. (eds). Micromorphology of Diatom Valves, Vol. XI with plates 1024-1148, Cramer, Vaduz, 299 pp.

LizardTech. 2002. Genuine Fractals software manual. 26 pp http://www.lizardtech.com.

McJonathan S. 2000. Overcome the limits of optical microscopy. R\&D magazine, October 2000: 73.
Schmidt A. 1874-1959. Atlas der Diatomeenkunde. Fortgesetzt von Schmidt M., Fricke Fr., Müller O., Heiden H. und Hustedt Fr. (eds), akademie-Verlag, Leipzig, 480 Pls.

Schumann J. 1862-1869. Preussische Diatomeen. Schriften der königlichen physikalisch-ökonomischen Gesellschaften zu Königsberg. Band 3 (1862), Band 5 (1864), Band 8 (1867), Band 10 (1869).

Simonsen R. 1987. Atlas and catalog of the diatom types of Friedrich Hustedt. Vols. 1-3:. Cramer, Berlin. 525 pp. 732 Pls.

Stoermer E.F. 1996. A simple, but useful, application of image analysis. J. Paleolim. 15: 111-113.

Valdecasas A.G., Marshall D. and Becerra J.M. 2002. Extended depth-of-focus algorithms in brightfield microscopy. Microscopy and Analysis September 2002: 11-13.

Wunsam S. and Bowman J.C. 2001. Economical digital photomicroscopy. J. Paleolim. 25: 399-403. 